\title{
A Review of Principles of Linguistic Change: Cognitive and Cultural Factors
}

\author{
Yubo Zhang \\ Southwest University, Inner Mongolia University, Huhhot, China \\ Email: nm159@139.com
}

Received 22 November 2013; revised 20 December 2013; accepted 31 December 2013

Copyright @ 2014 by author and Scientific Research Publishing Inc.

This work is licensed under the Creative Commons Attribution International License (CC BY). http://creativecommons.org/licenses/by/4.0/

(c) (i) Open Access

\begin{abstract}
Labov's Principles of Linguistic Change: Cognitive and Cultural Factors is the third volume of his trilogy, the first two dealing with internal factors and social factors controlling linguistic change. Volume 3 examines the cognitive and cultural factors responsible for linguistic change. The present volume explores into the internal factors discussed in Volume 1, concentrating on the cognitive factors determining the capacity of linguistic system to transmit information. This volume also investigates the social factors considered in Volume 2, moving from the inquiry of face-to-face interaction in local communities to a further examination of cultural patterns in a wide range and on a diachronic basis.
\end{abstract}

\section{Keywords}

\section{Linguistic Change; Cognitive Factors; Cultural Factors}

\section{Introduction}

Under the authorship of William Labov, one of the founders of modern sociolinguistics, Principles of Linguistic Change: Cognitive and Cultural Factors (published by Wiley-Blackwell in 2010) is the third volume of his trilogy. The first and the second volumes deal specifically with internal factors and social factors that control linguistic change. With a wider scope and a broader database than the first two volumes, Volume 3 examines the cognitive and cultural factors responsible for linguistic change. The three volumes together symbolize the lifework of a world-famous linguist "who has dominated modem thought in the field as nobody else has, with the single exception of Noam Chomsky" (Görlach, 1997: 156). Just prior to this book, Labov coauthored with his two partners Atlas of North American English (Labov, Ash, \& Boberg, 2006, ANAE henceforth), and found that regional divergence in North American English had increased. This raises a series of questions: What are the consequences of this increasing divergence? What are the origins of such change? And what are the forces that 
continue to drive divergence over time? The present volume is intended to answer these questions. In response to these questions, the volume explores into the internal factors discussed in Volume 1, concentrating on the cognitive factors determining the capacity of linguistic system to transmit information. Equal endeavors are made to further investigate the social factors considered in Volume 2, moving from the inquiry of face-to-face interaction in local communities to a further examination of cultural patterns in a wide range and on a diachronic basis. Along with the search for the cognitive and cultural factors responsible for the linguistic change are the author's probes into other important arguments concerned, including convergence and divergence, determination of linguistic change, distinction between the transmission and diffusion of linguistic change, etc.

The present volume consists of an introductory chapter, a concluding chapter and four parts. Part A (Chapters 2 - 4) investigates the cognitive consequences of sound changes that identify and symbolize the dialects of the major cities of Philadelphia, Chicago and Birmingham. Part B (Chapters 5 - 12) provides a panorama of the life history of linguistic change. Part C (Chapters 13 - 14) reviews the questions raised in Volume 1, "Words Floating on the Surface of Sound Change," in quest of lexical effects in sound change. Part D (Chapters 15 - 16) deals with the definition of and the distinction between two concepts of linguistic descent: transmission and diffusion. Chapter 17 servers as the conclusion of the whole volume.

In Labov's designations of cognitive factors and cultural factors, the former are referred to the processes of cognition in the limited sense: the ability to decode what is being said by recognizing the linguistic categories, and the latter are directed to the combination of the linguistic change and broader social patterns which are free from face-to-face interactions.

In Part A, Labov applies an array of observations and experiments so as to clarify whether linguistic changes under way have a significant effect on the ability to identify the phonemes in speech streams, and therefore recognize the words intended by the speaker.

In Chapter 2, Labov commits himself to a set of 869 natural misunderstandings collected from everyday life, with an exhaustive analysis of the misunderstandings in the aspects of the corrections, roles, commonness and effect of sound change (mergers or chain shifts) in misunderstanding. He admits that the observation method of collecting the misunderstandings "plainly has limitations" (46). "The data do give us an idea of the relative number of misunderstandings due to dialect motivation, though we cannot be sure of the extent to which the observers' attention was biased towards cases of this type. Most of the misunderstandings noted here crossed dialect boundaries; there are relatively few among speakers of the same dialect, but the comparison is not a controlled one." Though with limitations, "the method we used here emerges as one valid way of capturing the cognitive consequences of linguistic change" (47). These limitations are overcome in the next two chapters (Chapters 3 and 4), in which controlled experiments are conducted on cross-dialectal comprehension.

The basic finding of these chapters is that the ongoing linguistic changes in Philadelphia, Chicago and Baltimore significantly interfere with cognitive processes, within the community as well as across communities (367). Therefore, an investigation of the origins, causes and driving forces behind linguistic change becomes necessary.

Chapter 5 revolves around the examination of the historical matrix from which current North American English sound changes are derived, searching for their "triggering events." Labov makes it clear that the causal character of a chain shift requires a bend in the chain of linguistic causality. And there proved to be numerous such bends in the history of linguistic changes. "They generally involve the removal a vowel from one subsystem and its insertion into another" (118-119).

The conclusion of Part A does not put an end to the discussion of cognitive factors. Chapter 6 is devoted to a further exploration concerning the cognitive principles governing linguistic change, with the underlying mechanism of probability matching included. It seems that shifts are able to accelerate, or at least maintain the operation of the phonological system, but mergers are not. Sound changes contributing to mergers can hardly improve the speakers' ability to identify meanings in a speech stream.

Divergence problems are divided into two types in Chapter 1. One is the existence of parallel developments after long separation, and the other is the problem of divergent developments in neighboring dialects which have never been separated. Chapter 7 deals with the cases of the second type in an attempt to characterize the common features of the forks in the road which lead to the increasing regional diversity of North American dialects (155). And Chapter 8 centers on the second step in the model in order to advance a general schema for divergence that may be useful for the study of change in other languages and in other societies (165).

Chapter 9 reviews the various proposals for the social factors stimulating linguistic change and demonstrates a 
wide variety of social structures correlating with a particular linguistic form, and concludes that the extent and uniformity of these changes must be accounted for by a cultural history that is at least in part independent of face-to-face interaction. Yankee cultural imperialism is investigated and the political, religious and cultural history of North/Midland is traced in Chapter 10 in an attempt to testify that "the unconscious shifting of vowel systems is reinforced by long-standing ideological oppositions on a national scale" (208). After raking up the history of the Northern Cities Shift in the Inland North (Chapter 9) and the religious and cultural history of that region (Chapter 10), Labov poses an increased possibility that "the continued influence of Yankee ideology contributes to the momentum of the Northern Cities Shift across the Inland North" (236).

Chapter 11 applies an experiment to test the association of the North/Midland opposition with ideological positions before the author arrives at the conclusion that, it is true that "language change may be local and reflect an immediate social motivation to reinforce local identity, but the language change in North America occurs on a much larger scale, where individual acts and motivations are irrelevant" (244).

The focus of language change study is supposed to be the change in progress, but Labov (Chapter 12) observes that "most changes are not in progress" and that "almost all features of currently spoken languages are the endpoints of completed changes".

Chapters 13 and 14 concentrate on the discussion of cognitive basis of phonemic categories. Drawing on the massive database of ANAE, Labov examines the regularity of sound change and confirms the phoneme, not the word, as the fundamental unit of sound change, which supports Bloomfield's formulation of the Neogrammarian view. The use of multiple regression analysis reveals that change affects all words in which a phoneme exists; but there still remain slight fluctuations from word to word that need illuminating.

Much of Chapter 14 concerns in detail the co-articulating disruption of phonemes and its binding force. When the integrity of a phoneme inflicts threats in a regular conditioned sound change, binding force will work by combining the allophones of a given phoneme and operates so as to counteract the disruptive effects of co-articulation.

Age differences in cognitive processing are the central topics of Chapters 15 and 16, in which discrimination is made between the linguistic forms by children and the diffusion of forms by adults, hence the distinction between the family-tree model and the wave model of change.

Definition and distinction of two concepts are clarified in Part D concerning linguistic descent, i.e., transmission and diffusion. Transmission is defined as "the product of children's cognitive capacities as language learners: it is the basic process responsible both for stability and for the regularity of change within the speech community" (11). Diffusion across speech communities is viewed as "the product of the more limited learning capacity of adults" (11). As adults do not acquire language as regular and faithful as children do, the results of such language contact are less regular and less consistent than transmission within the community. Chapter 15 focuses on diffusion across geographically separate communities, and Chapter 16, on diffusion across separated communal groups within the community.

The last chapter of this volume (Chapter 17) summarizes the whole volume, in which arguments are reexamined and more detailed views are provided concerning the relation of linguistic change to animal communications and the functions of language, etc.

A striking feature of this volume is its comprehensive application of incisive research methodologies: data collecting involves interviews, experiments, observations, anonymous surveys, corpus etc., and in data analyzing, qualitative, ethnographic, multivariate analyses etc. are employed, with multiple regression analysis and empirical studies included as well. And another striking feature is the application of very detailed and convincing arguments to the unfolding views. Sociolinguistics as the main field, the book is also involved with many other disciplines: historical linguistics, dialectology, pragmatics etc.

One comment on Volume 1 by Professor Görlach is equally true to Volume 3 under review: "The great attraction of the book is certainly that Labov has with great persuasion drawn together the findings" "to illustrate a theory of linguistic change". "It is consistent and coherent, all arguments being within a Labovian paradigm" (Görlach, 1997: 159).

\section{Acknowledgements}

My sincere gratitude goes to Professor Bingjun Yang, my supervisor, both for his instructive advice and encouragement. 


\section{References}

Görlach, M. (1997). Reviews: Principles of Linguistic Change: Internal Factors. Journal of English Linguistics, 25, $156-159$. Labov, W. (2010). Principles of Linguistic Change: Cognitive and Cultural Factors. Hoboken, NJ: Wiley-Blackwell. 